\title{
Uma pax monetaria? Impasses do sistema monetário português no tempo dos Filipes (1580-1640)
}

\author{
Pedro Puntoni ${ }^{1 *}$ \\ ${ }^{1}$ Universidade de São Paulo, São Paulo/SP - Brasil
}

\section{RESUMO}

No século XVII, o fenômeno monetário era central para o entendimento da economia, notadamente no Mundo Ibérico, onde os fluxos de metais americanos exigiam uma posição sobre seu impacto nas atividades mercantis e produtivas, e na sua articulação com o comércio ultramarino e a gestáo das economias coloniais. Este trabalho procura entender os impasses da política monetária filipina para o reino e o Império de Portugal. A União de 1580 manteve, além das "leis, estilos, liberdades, isençôes, casa Real e ofícios" da Coroa portuguesa, a moeda com cunho português. Assim, Filipe II permitia que o seu direito exclusivo (regalia) de cunhar a moeda fosse interpretado na mesma chave da conservação da identidade econômica e jurídica de Portugal. Durante todo o período, os Filipes não alteraram o valor da moeda portuguesa, estabilizando o câmbio do real em relaçáo às outras unidades de conta europeias. A chegada em grande quantidade da prata americana, por outro lado, permitia a expansão do meio circulante de Castela, que acabou, no período, intoxicando o meio circulante português. Esse arranjo instável coloca as bases para a transformação que se seguirá no período da Restauração, com sucessivas mutações monetárias.

Palavras-chave: história monetária; Portugal; União Ibérica; política monetária.

DOI: http://dx.doi.org/10.1590/2237-101X02104310.

Artigo recebido em 21 de dezembro de 2018 e aceito para publicação em 21 de junho de 2019.

Este texto é resultado parcial da pesquisa "Moeda e Império: o sistema monetário português no Ultramar - Brasil, Índia e África (1640-1688)", apoiada pelo CNPq (314044/2018-3 e 405131/2018-6) e pela Fapesp (2015-22557-2). Uma primeira versão foi discutida no GEHIM-USP / GP-UNIFESP "A Monarquia Hispânica e o Império dos Filipes (1580-1640)" e também no ST “O espaço luso-atlântico em perspectiva global: circulação, poder e redes no contexto da união das coroas ibéricas, 1580-1640”, realizado no VII EIHC (Natal, 2018). Agradeço aos colegas a leitura atenta e, sobretudo, pelas críticas e sugestóes.

* Professor da Universidade de São Paulo / Departamento de História, São Paulo/SP - Brasil. E-mail: puntoni@usp.br. ORCID: https://orcid.org/0000-0002-6451-281X. 


\section{A pax monetaria? Dilemmas of the portuguese monetary system under the habsbourgs (1580-1640)}

\section{ABSTRACT}

In the seventeenth century, the monetary phenomenon was central to the understanding of the economy. Notably, in the Iberian World, where the flows of metals of America demanded a position on their impact on the mercantile and productive activities, and their articulation with the overseas trade and the management of the colonial economies. This work tries to understand the dilemmas of the monetary policy of the Habsburgs for the kingdom and the Empire of Portugal. The Union of 1580 maintained, in addition to the "laws, styles, freedoms, exemptions, royal house and offices" of the Portuguese Crown, the Portuguese currency. Thus, Philip II allowed his exclusive right to coinage to be interpreted in the same key of the conservation of the economic and juridical identity of Portugal. Throughout the period, the Philips did not change the value of the Portuguese currency, stabilizing the exchange rate of the real against the other European units of account. The large arrival of American silver, on the other hand, allowed the expansion of the monetary mass in Castile that ended up intoxicating the Portuguese circulating medium. This unstable arrangement puts the foundations for the transformation that will follow in the Restoration period, with successive monetary devaluations.

Keywords: monetary history; Portugal; Iberian Union; monetary policy.

\section{Una ¿Pax monetaria? impases del sistema monetario portugués en el tiempo de los Filipes (1580-1640)}

\section{RESUMEN}

En el siglo XVII, el fenómeno monetario era central para el entendimiento de la economía. Notoriamente, en el Mundo Ibérico, donde los flujos de metales americanos exigían una posición sobre su impacto en las actividades mercantiles y productivas, y en su articulación con el comercio ultramarino y la gestión de las economías coloniales. Este trabajo pretende entender los impases de la política monetaria filipina para el reino y el Imperio de Portugal. La unión de 1580 mantuvo, además de las "leyes, estilos, libertades, exenciones, casa Real y oficios" de la Corona portuguesa, la moneda con cuño portugués. Así, Felipe II permitía que su derecho exclusivo (regalía) de acuñar la moneda fuese interpretado en la misma llave de la conservación de la identidad económica y jurídica de Portugal. Durante todo el periodo, los Filipes no alteraron el valor de la moneda portuguesa, estabilizando el cambio del real en relación a las otras unidades de cuenta europeas. La llegada en gran cantidad de plata americana, por otro lado, permitía la expansión del medio circulante de Castilla que acabó, 
en el periodo, intoxicando el medio circulante portugués. Este arreglo instable coloca las bases para la transformación que se seguirá en el periodo de la Restauración, con sucesivas mutaciones monetarias.

Palabras clave: historia monetaria; Portugal; Unión Ibérica; política monetaria.

Moedas ao fogo! Assim terminou a efêmera soberania de D. Antonio nos Açores. Com efeito, em julho de 1583, quando os espanhóis entraram na cidade de Angra - sob o comando do Marquês de Santa Cruz, dom Álvaro de Bazán y Guzmán - destruíram todas as peças monetárias que haviam sido cunhadas com o nome de D. Antonio. Para os espanhóis, essa moeda era tida como "falsa, mala y adulterina", e um bando de Filipe II determinava que fosse queimada e que se alguém fizesse uso dela ou permitisse que ela corresse, pagaria com a pena de morte 1 . O testemunho de Mosquera de Figueroa, que acompanhava as tropas de d. Álvaro, surpreende. Segundo ele, os soldados jogavam as moedas ao fogo, como prova de sua lealdade e consideração:

E, depois de se haver publicado o bando, havia no palanque um braseiro ou tina de fogo aceso, e o capitão Andres de Vega, aguazil real desta Armada e Exército, jogou naquele fogo moedas de ouro, prata e cobre; e feita esta solenidade, toda a infantaria e gente de guerra e mar, de que estava cheia a praça, começaram a lançar na parte do tablado onde estava o fogo toda a moeda de Dom Antonio, que em seu poder tinham, de tal sorte e em tanta quantidade, que sem perdoar ao ouro nem prata, por uma e outra parte parecia que chovia moeda, que durou mais de meia hora o lançar-se copiosamente; o que foi um espetáculo de consideraçáo, e uma consideração de lealdade e amor que os Espanhóis tem ao seu Rei, mais do que as outras naçôes $[\ldots]^{2}$ (MOSQUERA DE FIGUEROA, 1596, p. 106-106v.).

\footnotetext{
${ }^{1}$ Sobre as moedas do Prior do Crato, veja o estudo de Renier Hubert Ghislain Chailon, D. Antonio, roi du Portugal, son histoire et ses monnaies, 1868; e o exame de Carlos Manuel Almeida de Amaral no Catálogo Descritivo das Moedas Portuguesas, 1977, tomo 1, p. 580-590.

2 "Y después de a verse publicado el bando, avia en el cadahalso um brasero o tina de fuego encendido, y el capitán Andres de Vega, alguazil Real desta Armada y exercito, echó en aquel fuego monedas de oro, plata y cobre: y echa esta solemnidad, toda la infantaria y gente de guerra y mar, de que estava llena la plaza, comenzaron à arrojar en el tablado a la parte donde estava el fuego, toda la moneda de don Antonio, que en su poder tenían, de tal suerte y en tanta abundancia, que sin perdonar al oro ni plata por una y outra parte parecia que llovía moneda, que duró mas de media hora el arrojar-la copiosamente que fue un espectáculo de consideración, y una consideración de la lealtad y amor que los Españoles tienen a sua Rey, mas que outras naciones [...]”. Minha tradução.
} 
A moeda aparecia, assim, como signo da usurpaçáo do trono pretendida pelo Prior do Crato, ou ainda, como malefício que na sua inconsistência material revelava a sua própria falsidade. Mas, que moedas eram essas?

Como bem sabem os numismatas (interessados na raridade dessas peças), durante a crise sucessória de 1580, o Prior do Crato, assumindo ser rei de Portugal, mandou cunhar moedas quando em seu refúgio em Angra, o que foi feito até 1583. Segundo Pedro Batalha Reis, D. Antonio, nos dois meses que passou em Lisboa - entre junho e agosto de 1580 - já teria mandado lavrar moedas de ouro e de prata, com pesos diminuídos. Moedas de 500 réis de ouro seriam cunhadas na relação de 80 por marco e os tostôes (100 réis) de prata a 40 por marco ${ }^{3}$. Assim, o marco de ouro que mandou cunhar D. Antonio passaria de $30 \$ 000$ réis para $40 \$ 000$ réis e o de prata de $2 \$ 650$ réis (REIS, 1946, p. 197 e ss.). A partir de 1582, o rei nos Açores mandou carimbar as peças circulantes com a marca "AÇOR" e dobrou o seu valor de face. Os particulares que tinham de levar suas moedas para receberem o carimbo perdiam metade do seu metal, sendo que todo o ganho ia para o monarca. Seu excessivo valor extrínseco levou à diversas falsificaçóes, como as feitas por comerciantes franceses (ARAGÃO, 1875, p. 60, p. 302 e ss.). De toda forma, eram moedas de circulação restrita, já que com valores muito levantados e sem a força de um poder soberano.

O jesuíta Antonio Cordeiro, na sua História insulana, conta como o lugar-tenente do rei, o Conde de Torre Vedras ${ }^{4}$ resolveu inventar uma casa real da moeda, colocando-a "no pátio do hospital da cidade [de Angra], com ministros e oficiais peritos". Tendo fabricado moeda de prata, ouro e cobre, o fez a levantando "toda em dobro": "as de ouro de 500 réis subiu a mil, as de mil a dois, as de prata de cruzado a dois cruzados, as de tostão a 2 tostóes, as de vintém a dois vinténs, e assim as mais de cobre" (CORDEIRO, 1717, \$304 ss.). Sua circulação foi muito restrita. Segundo o relato de Mosquera de Figueroa, a situação era ainda pior:

[...] a moeda é feita de cobre em sua maior parte, e para a fabricar, desfizeram todas as bacias e copos de cobre que houvessem nas ilhas, e agora o estão esperando de Flandres para fazer moeda dele, porque não há moeda de prata, nem da antiga, nem da nova. Corre uma moeda de ouro, que antes valia cinco tostöes [500 réis], e a tem levantado para cinco cruzados [2\$000 réis]; e uma moeda de cobre, que em Portugal valia 3 réis, o que equivale a 3 maravedis, elevou-a a

\footnotetext{
${ }^{3}$ Foi no tempo de Afonso III (1248-1279) que se consolidou o uso do "marco de Colonia" como o padrão de peso para o sistema monetário em Portugal. O marco era o padrão aceito em amplos espaços da Europa ocidental para aferir o peso dos metais preciosos. Um marco era dividido em onças (8), oitavas de onça (64) ou grãos (4.608). De valor, contudo, variável não se formaliza como um padrão universal. Em Portugal, o marco pesava 229,5 gramas; em Castela, 230 gramas. Nesse sentido, segundo Raúl de Couvreur (1944), pode-se concluir por uma igualdade do "marco monetário luso-castelhano; veja também COUVREUR, 1945, p. 5-10; e I BRU, 1984, p. 105-119.

${ }^{4}$ Manuel da Silva Coutinho (1541-1583), o primeiro Conde de Torres Vedras, nasceu em Santarém, de família nobre. Tendo participado da Batalha de Alcântara (25 de agosto de 1580), como general, acompanhou D. Antonio - o Prior do Crato - no seu exílio na França e na Inglaterra, indo para Angra em 1582.
} 
dez; e a de três blancas a cinco maravedis; mas cada uma destas há de ser marcada pela casa de moeda com a figura de um açor; e outra moeda que eles fizeram de cobre novamente, com o hábito de Santiago gravado nela: vale quatro vinténs, que são oitenta maravedis, e esta moeda é tão grande quanto meia moeda das que valem em Portugal três blancas ${ }^{5}$ (MOSQUERA DE FIGUEROA, 1596, p. 29v.).

Segundo este autor, as moedas eram táo fracas $^{6}$ que os poucos navios de mercadores que chegaram a Angra preferiram trocar seus produtos por açúcar ou "outras mercadorias da terra", não aceitando o dinheiro como pagamento ("retrocediendo de la especie al genero"). Dessa forma, toda a moeda velha (mais forte) foi retirada da Ilha. Por outro lado, como todos tinham medo de que Manuel da Silva Coutinho lhes tomasse o metal, era de se esperar que ele fosse todo desviado (MOSQUERA DE FIGUEROA, 1596, p. 79).

A conquista da Ilha foi, como a de Lisboa, parte da violência militar empregada por Filipe II para fazer valer seu controle do território e das gentes portuguesas. Ao contrário do que tem afirmado a historiografia, Rafael Valladares mostrou como foi decisiva a invasão comandada pelo Duque de Alba, destacando o episódio da Batalha de Alcântara, em agosto de 1580 (VALLADARES, 2010, p. 26 e ss.) ${ }^{7}$. A resistência, encarnada na figura do sobrinho de D. Henrique - coroado rei em Santarém - manteve-se no Norte de Portugal até que, da Inglaterra para a França, resolveu fixar-se nos Açores em 1582. A expressão da soberania era, entre outras, manifesta na cunhagem de novas moedas com a face de D. Antonio. Quando nos Açores, muito mais fez cunhar. Como vimos, moedas de pouco peso ou má liga. Sabemos que, em fevereiro de 1581, Filipe II mandava que as peças lavradas com o nome de $\mathrm{D}$. Antonio não corressem em lugar algum, porque "lavrada por pessoa que para isso não tinha poder nem autoridade" (LEI do ano de 1581, 1738, p. 336338; ALVARÁ..., 4 fev. 1581). Nesse momento, não se sabe exatamente quem as fazia. Mas Filipe II em Lisboa mandava que fossem todas recolhidas e pagas pelo seu peso. Por fim, como vimos, quando as tropas do Marquês de Santa Cruz entraram em Angra, logo se organizou uma "solemnidad" para se jogar no braseiro as moedas de ouro, prata e cobre que tivessem por inscrição ANTONIUS I D. G. REX. PORT. O metal, com certeza, seria depois recolhido. Segundo Manuel de Faria e Sousa, se a moeda foi queimada "em grande cópia",

\footnotetext{
5 "[...] la moneda es de cobre la mayor parte, y para la fabricar han deshecho quantas bacias y vasos de cobre ay en las islas, y ahora lo esperan de Flandes, para hacer moneda dello, porque no ay moneda de plata de la vieja, ni de la nueva. Corre una moneda de oro, que antes valia cinco tostones, y han la subido a cinco cruzados [ $2 \$ 000$ réis]; y una moneda de cobre, que en Portugal valia 3 reis, que es lo mismo que 3 maravedis, han la subido a diez; e la de tres blancas a cinco maravedis; pero cada una destas a de ser marcada pela casa da moneda com la figura de un açor; e outra moneda que han hecho de cobre nuevamente, con el habito de Santiago en ella: vale quatro veyntenes, que son ochenta maravedis, y esta moneda es tan grande como media moneda de las que valen em Portugal tres blancas". Minha tradução.

${ }^{6}$ Isto é, com pouco metal em relação ao valor que pretendiam expressar em moeda de conta.

${ }^{7}$ Sobre os Açores, veja o capítulo V, p. 145-160.
} 
ao final "não se perderia nada, porque Castela, para satisfazer sua cobiça, nunca perdeu muito" (SOUSA, 1680, p. 93).

A casa da moeda do conde de Torres Vedras foi para os ares, provavelmente por arte de uma mina preparada a mando do próprio, antecipando o ataque espanhol. $\mathrm{O}$ conde, quando preso, foi acusado de traição e degolado em agosto de 1583 . Mas as moedas fracas de D. Antonio não eram apenas ali cunhadas. Algumas vinham de outras oficinas, notadamente da aliada França. Depois que o Marquês de Santa Cruz fez velas, atracou em Angra um navio francês com moedas de cobre gravadas com o nome de $\mathrm{D}$. Antonio. O desavisado capitáo, envolvido no negócio dessa moeda, deixou-se capturar e acabou condenado à morte (MAURO, 1989, p. 172).

Mesmo no exílio, em França, D. Antonio ainda tentaria lavrar moeda para seu uso. Ele procurava demonstrar, na adversidade e mesmo na derrota, a sua legitimidade como soberano. Ou ainda, como se encontrava privado de todos os rendimentos de Portugal, via nesta sua prerrogativa régia - a de cunhar moeda - a possibilidade de auferir algum ganho. A tradução que ele podia fazer entre o metal (mercadoria) e a moeda de conta (real), lhe permitia estirar ao máximo essa relação para conseguir algum valor em seu tesouro particular. Pedro Batalha Reis publicou um interessante documento que revela que D. Antonio havia solicitado de Henrique III autorização para cunhar moeda em França. A Cour des Monnaies reagiu de forma negativa, alertando ao rei de França que essa concessão poderia ser prejudicial. Um dos argumentos era de que era "contra a autoridade do rei bater moeda neste reino com o brasão e armas de um príncipe estrangeiro", além disso, "seria contra a honra de sua majestade permitir bater as ditas moedas de mesma marca e pior qualidade que não seja aquela das que se fundem no país de onde se originam as marcas" (REIS, 1946, p. 252-253) ${ }^{9}$. Pedro Batalha Reis acredita que essas peças provavelmente haviam sido cunhadas em algum ponto dos Países Baixos, onde efetivamente, a partir de outubro de 1583, seriam lavradas em uma casa de moeda improvisada na cidade de Gorinchem (Gorcum) algumas peças de ouro e de prata - muito depreciadas e de circulaçáo incerta (p. 257-280).

\section{Conservar a moeda de Portugal}

O expurgo das moedas cunhadas com o nome de D. Antonio fazia parte da conquista do espaço soberano da monarquia portuguesa pelo Rei Habsburgo - que manteria, contudo, o regime monetário português na sua autonomia. Em maio de 1581, Filipe II, primeiro de Portugal, jurou guardar os foros do reino nos capítulos apresentados nas Cortes em Tomar.

\footnotetext{
8 “[...] no se perderia nada, porque Castilla, por hartar su codicia nunca desperdició mucho". Minha tradução.

9 "Delibération de la Cour des Monnaies et du Conseil du Roi, relatives aux monnaies du Roi de Portugal", Paris, 19 abr. 1583. Minha tradução.
} 
Segundo Ericeira, em resumo, tratava-se de "conservar a Coroa de Portugal nas leis, estilos, liberdades, isenções, moeda, casa Real, e ofícios dela, de que usavam os Príncipes naturais do Reino" (MENESES, 1751, p. 34). Sobre a moeda, particularmente, os capítulos gerais das Cortes garantiram que "todo ouro e prata que entrasse neste reino e domínios de Espanha, se poder[ia] lavrar em moeda com o cunho de Portugal" ${ }^{10}$. Assim, se o monarca assumia o domínio de Portugal e suas conquistas, liberalmente permitia que o seu direito exclusivo (regalia) de cunhar a moeda fosse interpretado na mesma chave da conservaçáo da identidade econômica e jurídica de Portugal; concretizada - nesse particular - na possibilidade de se manter o símbolo e a matéria da moeda nacional. Parte de uma estratégia mais ampla, como mostrou Pedro Cardim, de respeito à individualidade política de Portugal, com a "manutenção do sistema jurisdicional e político português” (CARDIM, 2014, p. 94 e ss.).

A possibilidade de assegurar a moeda portuguesa significava não apenas manter a fábrica de tostôes e meio tostôes de prata, moedas e quartinhos de ouro, mas sobretudo de garantir a utilização da moeda de conta, o real, que fora consolidada há cerca de $150 \operatorname{anos}^{11}$. Todos os contratos e obrigaçóes, direitos e tributos, preços e referências, estavam consignados por essa unidade de conta, que se expressava - em determinados momentos das trocas - em moedas especificamente nacionais, que constituíam parte do sistema monetário português. Mais ainda, Filipe II concedeu que a tipologia das moedas nacionais portuguesas em nada se alterasse, como havia acontecido com Navarra. Como notou José Maria de Francisco Olmos, a partir de 1586, é o brasão português que iria aparecer nas moedas cunhadas em Segovia, seguindo a decisão de 1566 (anterior à conquista de Lisboa) de incluir as armas de Portugal às Grandes Armas da Monarquia Hispânica ${ }^{12}$.

Se fosse possível olhar para a oferta monetária portuguesa - isto é, o montante de dinheiro circulante no espaço econômico do Império português - no final do século XVI, certamente veríamos uma enorme predominância das peças castelhanas em detrimento das cunhadas em Lisboa. Desde os últimos anos dos Avis, antes da conquista de Portugal por Filipe II, o sistema monetário português já era inundado pelas moedas cunhadas em Castela ou na América e marcado profundamente por sua dependência em conseguir a prata necessária para fechar os circuitos abertos com o comércio ultramarino, notadamente com o Oriente. A tentativa de D. Sebastiáo, com as leis de 1558 e 1560, de consolidar toda a base circulante no reino, em valores novos e mais estáveis, não parece ter resultado. De toda forma, não só faltava metal para fabricar novas peças, mas sobretudo confiança entre os agentes do mercado, os verdadeiros usuários das peças de ouro e prata, que preferiam manter sua

10 "Capítulos gerais oferecidos pelos estados dos povos nas cortes que o dito rei [Filipe II] convocou em Tomar em o mês de abril de 1581”, veja em VISCONDE DE SANTARÉM, 1828, 2ª parte, p. 79.

${ }^{11}$ Sobre o assunto, veja meu artigo "Da libra ao real: sobre a formação do sistema monetário português (11851580)", 2019.

${ }^{12} \mathrm{E}$ assim será até $\mathrm{o}$ ano de 1683 , quando foram finalmente retiradas as armas portuguesas das moedas e dos documentos dos monarcas castelhanos. Cf. FRANCISCO OLMOS, 2009, p. 61-70. 
proximidade com as peças de Castela, estáveis desde o final do século XV e que, por isso e por sua grande oferta, se consolidavam como um padrão realmente universal. Segundo Vitorino Magalhães Godinho, em meados do século XVI, não só Portugal, mas “todo o mundo entretecido pelas grandes rotas marítimas, ou pelas caravanas das cordilheiras montanhosas e estepes euro-asiáticas - estava submerso pela maré enchente dos reales de a ocho (piastras, de 27,2 g) e reales de a cuatro". Nos decênios seguintes, assistimos a uma intensa alteração da "geografia mundial dos metais preciosos e numerário". Na imagem do historiador, com a consolidação da economia-mundo, a China operaria "como bomba aspirante de toda a prata

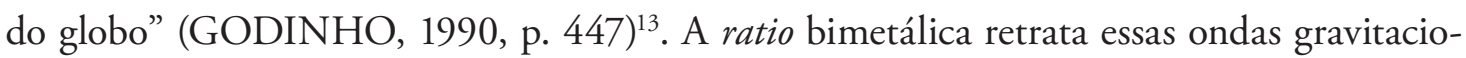
nais do sistema monetário mundial: na China, a valorização da prata, em relação ao ouro, é máxima: chegando entre 6:1 e 8:1 - enquanto que, na Europa, ela está um pouco acima do 12:1. Como mostraram Dennis Flynn e Arturo Geraldez, essa primeira fase da evolução do mercado global de prata - entre 1540 e 1640 - se caracterizou justamente pela primazia da demanda chinesa, resultado do alto preço relativo da prata e também das próprias mercadorias orientais. Na década de 1640, assistimos a uma convergência global dos preços relativos da prata e do ouro. No entanto, a balança de comércio com a China continuou deficitária e a prata americana manteve o seu destino oriental (FLYNN e GERALDEZ, 2002).

Em Portugal, o que assistimos é o quase naufrágio da moeda nacional, suplantada pela realidade necessária de uma moeda que se construía como universal. Ao ponto que Domínguez Ortiz pensava que a prata americana havia contribuído para criar uma "espécie de unidade econômica do mundo", de modo que o Império Espanhol poderia ser caracterizado, antes de mais nada, como um "império monetário" (DOMÍNGUEZ ORTIZ, 1971, p. 303) ${ }^{14}$. Visão um pouco exagerada, uma vez que a Espanha servira mais como placa giratória desse metal, e, como mostrou Cipolla (1996), não conseguiu manter "qualquer poder sobre esta massa monetária". Antes disso, em um primeiro momento, Portugal e seus parceiros em Itália e Antuérpia acabariam controlando os fluxos do metal $^{15}$. Devemos também notar, a partir da sugestão de Braudel, que, tirante o entesouramento cada vez maior ("goela permanentemente aberta, comparável à da Índia 'ávida de prata"”), a ampliação do comércio implica a aceleração da circulação monetária ${ }^{16}$; ou ainda

\footnotetext{
${ }^{13}$ Ernest Van Veen vê na posição de Godinho algum exagero. Em seu estudo sobre o declínio português na Ásia, acredita que - pelo menos para o período que vai de 1580 a 1645 - o fluxo de prata para a China não fora determinante dos destinos do Império Ibérico. Para este autor, nos anos de 1630, cerca de $67 \%$ da prata importada da América teria permanecido na Europa (VAN VEEN, 2000, p. 240 e ss.). O debate de Van Veen, na verdade, é com o trabalho de FRANK, 1998.

${ }^{14}$ Veja também MARICHAL, 2007, p. 107-121.

${ }^{15}$ Segundo ele, "quem manobrou a distribuição e as correntes de reales não foi a Espanha, mas sim Génova e Portugal, em um primeiro lugar e, depois, as companhias das Índias - a holandesa e a inglesa” (CIPOLLA, 1996, p. 116).

${ }^{16}$ Sendo assim, "quando no século XVI houve crescimento econômico acompanhado da 'revoluçáo dos preços', a velocidade de circulaçáo aumentou ao mesmo ritmo da equação de Irving Fischer” (BRAUDEL, 1996, p. 411). A referência é a teoria quantitativa da moeda: a massa monetária (M) multiplicada pela sua
} 
como resultado do próprio desenvolvimento das moedas fiduciárias e dos mecanismos de crédito e compensação monetária.

\section{A prata do Novo Mundo}

O acesso à prata americana foi, sem dúvida, um dos elementos mais decisivos para alinhar os interesses dos mercadores e de grande parte da nobreza a eles associados com a arrogação da coroa de Portugal por Filipe II. Godinho nos mostra como a União das Coroas, "desejada pelas classes dirigentes portuguesas", resultou, entre outras, na tomada, por parte de um consórcio de portugueses, do asiento para o fornecimento de escravos para às Índias de Castela, "um dos maiores negócios do mundo" (GODINHO, 1981, p. 98). Até o golpe de 1640, o tráfico negreiro para a América, abastecendo as minas e fazendas do Novo Mundo Espanhol, será controlado por comerciantes portugueses, que trazem, com isso, a prata para os circuitos exclusivos do sistema colonial lusitano. Os Habsburgos não deixaram de cunhar moedas portuguesas, imprimindo a sua marca no meio circulante do reino. Em 1584, Filipe I (de Portugal) manda cunhar novas moedas de ouro, com a inscrição PHILlipus D.G REX PORTUGalia. Essas moedas seriam o cruzado, dois cruzados e quatro cruzados. Feitas (provavelmente) com a mesma lei de $225 / 8$ quilates do tempo de D. Sebastiáo, seus valores arredondados para 400, 800 e 1.600 réis, respectivamente, resultavam em pequena desvalorização. A moeda de um cruzado seria feita com o peso de 61 grãos e 7/12 de grãos, o que lhe tirava $8 / 12$ grãos de metal em comparação com o cruzado "novo" de D. Sebastião (LEI do ano de 1584 , 1738, p. 340-342).

A Espanha náo teria dificuldade em encontrar o metal para cunhar essas novas peças. A descoberta das minas no serro de Potosi, em 1545, permitiu efetivamente inundar a Europa com a prata do Peru ${ }^{17}$. E o metal extraído no México também abundava. Em grande medida, essa prata, que finalmente chegava em imensa quantidade na península, era o que permitia a expansáo das trocas mercantis e, sobretudo, a intensificação com os mercados do Oriente. Nesse quadro, o meio circulante português se via, contudo, intoxicado pela presença das peças de prata já previamente cunhadas em Castela ou no Novo Mundo. Essa imensa maré de prata que invadiu a Europa, e o mundo, efetivamente sufocou a organizaçáo e expansão de uma estrutura autônoma e soberana em Portugal - e em outras praças. Acredito que, nesse momento, o ainda incipiente sistema monetário português não teria como resistir a essa hipertrofia do sistema espanhol que, inundando o mundo com seus reales, náo menos

velocidade de circulação $(\mathrm{V})$ seria igual a volume de transaçôes monetárias $(\mathrm{T})$ multiplicada pelo seu nível médio de preço (P): MV=PT.

${ }^{17}$ Sobre a produçáo de prata em Potosi, veja, entre outros, HANKE, 1956. Para o fluxo de prata americana, veja HAMILTON, 1934; GARNER, 1988; BARRET, 1990; STEIN e STEIN, 2000; TEPASKE, 2010; e, mais recentemente, o livro de LANE, 2019. 
atravessava todas as trocas e operaçóes de crédito realizadas no espaço econômico lusitano. Esse é um elemento importante a ser considerado nos termos do pensamento mercantilista que se anuncia.

\section{"A maré enchente dos reales"}

Paradoxalmente, a forte presença dos reales singelos preocupará a coroa, na medida em que circulam muitas peças cerceadas e, portanto, com menos peso. Essa condição enfraquecida do meio monetário em Portugal no contexto da União Ibérica é algo que ainda está para ser estudado. De toda forma, é possível concluir que mesmo a presença dessas peças de Castela era insuficiente para cumprir com as necessidades do comércio - sobretudo, do comércio com o Oriente. Se as Cortes em Tomar tinham conseguido manter a possibilidade de se continuar a fábrica de uma moeda nacional, não se ia além dessa possibilidade. Se havia prata circulando em Portugal, era sobretudo já amoedada, de forma que, concretamente, náo havia no reino metal para fazer sua Casa da Moeda funcionar. Em 1583, um despacho do secretário do Estado, Antonio de Eraso, a Filipe II, dá conta que haviam sido enviados 10 mil marcos de prata em pasta para Lisboa, a fim de que fossem lavradas moedas, "por oficiales descuidados, desusados e sin ferramientas" (DESPACHO, 23 out. 1583). Como vimos, o nome del-rei, Filipe I de Portugal já estava, desde 1584, em uma série das moedas de ouro. Mas nenhuma mutação foi feita nos (poucos) tostóes, meio tostốes e vinténs que ainda circulavam. Temos notícia de que, já em 1588, a coroa havia ordenado o levantamento da moeda de prata portuguesa, fazendo-se agora 28 tostôes com um marco de prata (CÓPIA..., 26 out. 1636). Náo sabemos, contudo, se efetivamente foram feitas essas moedas mais fracas. Alguns anos depois, já no reinado de Filipe III, o alvará de 13 de setembro de 1606 dava instruções para que a Casa da Moeda de Lisboa pudesse fundir moedas com a prata levada por particulares. A justificativa era que a falta que há das moedas de prata em Portugal era porque "a que vem de Castela em reales se leva para a Índia e outras partes fora do Reino". O alvará determinava a cunhagem de peças com menor peso, portanto, implicando numa quebra da moeda de prata. Ao dono do metal, seriam pagos $2 \$ 800$ réis pelo marco de prata, sendo que 100 seriam para a fábrica da moeda. Foram feitos tostóes, meio tostôes e vinténs de prata. Como os tostôes deveriam agora ter o peso de duas oitavas e 20 e 9/14 grãos, essas novas peças pesariam 28 grãos a menos das que vinham sendo cunhadas no tempo de $\mathrm{D}$. Sebastiấo. Uma diminuição de cerca de $14 \%$ da matéria da moeda. Os meio-tostôes, pesando uma oitava e 10 e $1 / 4$ grãos, e os vinténs, com 33 e 1/14 grão, praticamente mantinham os pesos das moedas que vinham sendo cunhadas (ALVARÁ de 13 set. 1606).

A desvalorização do tostão, certamente, vinha no sentido de manter essas peças circulando dentro do Reino de Portugal, confirmando a exclusividade das peças de prata castelha- 
nas no comércio com o ultramar. Para garantir isto, em janeiro de 1612, Filipe III proibiu totalmente a circulação das peças de Castela no reino de Portugal. Seus donos deveriam levá-las para serem refundidas. Sendo moradores de Lisboa, o prazo para tanto era de quatro dias! Os oficiais deveriam pesar as peças e aquelas que estivessem cerceadas seriam "cortadas" para valerem, então, apenas o seu peso em metal. O que, por determinação do Rei, não poderia valer menos de $2 \$ 620$ réis o marco (LEI do ano de 1612; LEI de 1612, 1738, p. 342-346). O que foi atenuado, em novembro de 1612, para o pagamento de pelo menos $2 \$ 730$ réis pelo marco de prata, para que os particulares assim "ficassem com mais dinheiro e menos perda" (ALVARÁ de 8 nov. 1612). A decisão veio depois das consideraçôes do Conselho da Fazenda, que via a troca forçosa da moeda como danosa aos comerciantes. Os dados levantados por Frédéric Mauro nos volumes dos Registros das entradas de ouro e de prata do Arquivo Histórico da Casa da Moeda permitem perceber essa retomada do funcionamento das fornalhas. De fato, se no primeiro decênio do século XVII entravam anualmente, em média, 9.000 marcos de prata para serem fundidos, em 1612 já são 28.700 marcos, chegando a 34.160 marcos em 1617. Efeito, na opiniáo do historiador, da execução prolongada das medidas de 1612 (MAURO, 1989, p. 163).

$\mathrm{Na}$ tabela e gráfico abaixo, reproduzimos os dados de Mauro. Os números, contudo, devem ser analisados com atenção. $\mathrm{O}$ historiador chega a afirmar que esses números dáo conta do estoque monetário português (oferta monetária), e que estudar sua variação permitiria entender sua evolução. Todavia, acredito ser equivocado fazer essa relação tâo direta. Não podemos identificar o metal que entra para ser lavrado na Casa da Moeda com toda a oferta monetária, entendido aqui como o conjunto das moedas em circulação. O que temos, com esses dados, são apenas indícios de contextos e situaçóes em que mais metal foi fundido e cunhado com as características da moeda nacional. Além disso, mesmo momento do século XVII, a contabilidade da Casa da Moeda é muito confusa. Como ainda não havia se implantado o sistema das partidas dobradas, a contabilidade está organizada por um sistema cronológico e de anotaçôes pessoais, identificando cada entrega. É, portanto, muito difícil recuperar a contabilidade exata do que entrou e foi lavrado. Há uma diferença, evidente, entre o registro dos metais que entraram na Casa da Moeda e aqueles que foram efetivamente amoedados. Dessa forma, este é um trabalho que tem ainda de ser feito para o longo século XVII ${ }^{18}$; o que, no caso do nosso estudo, exigiria ampliar o recorte, recuando para o período anterior à União Ibérica, no tempo das reformas sebásticas de 1558-1560. Para o período de 1515-1572, temos os dados levantados por Vitorino Magalhães Godinho (1981, p. 61 e p. 88). E não podemos, por outro lado, superestimar o papel da Casa da Moeda como operadora do meio circulante. Muito ao contrário. Ela náo tinha ainda o protagonismo no

\footnotetext{
${ }^{18}$ Para o século XVIII, confira GODINHO, 1955, com base nos números publicados por SOUZA, 1873. Rita Martins de Sousa (2005, p. 94 e ss.), em trabalho mais minucioso com as fontes, corrigiu os dados de Godinho e contabilizou novamente a amoedaçáo de prata, ouro e cobre com destino ao reino.
} 
processamento e na gestão da totalidade do sistema monetário português. Como sugerimos, a maior parte do meio circulante era formado, na dimensão mais alta (moedas de ouro e, sobretudo, prata) por peças de Castela. São reparos que não podem, contudo, paralisar o historiador do mundo econômico da época moderna. Apenas deixar-nos atentos e críticos para os resultados já obtidos e acumulados.

Feitos esses reparos, vamos acompanhar, ainda, os números reunidos por Mauro. Nos anos seguintes, a Casa da Moeda volta a registrar entradas menores de prata, chegando ao ponto mais baixo em 1622, com apenas 2.780 marcos de prata. A retomada dos trabalhos, a partir de 1623, seria o resultado - ainda na leitura de Mauro - da chegada da prata de Sevilha, em razão de uma licença expedida (çédula de saca) por Madrid (MAURO, 1989, p. 163). Não sabemos ao certo, mas é possível que a criação da Companhia de Comércio da Índia, em 1628, estaria na base dessa capitalização do sistema monetário português, com a necessidade que se colocava de cunhar moedas nacionais, sobretudo de prata, para a evolução dos negócios com o Oriente. Essa é a sugestão de Claudio Marsilio, em recente trabalho, no qual procura relacionar os contratos de asiento com a atividade de algumas oficinas monetárias na Europa (MARSILIO, 2015, p. 28).

A Companhia teve vida curta, isto é certo, mas os picos de entrada de prata (130.350 marcos em 1627 e 98.090 em 1628) devem estar relacionados com essa particular aventura. Somente a prata que entrou em 1628 permitiria a cunhagem de 686 mil cruzados, em moedas portuguesas. Estima-se que, nos anos de 1620, cada navio português transportava cerca de 100.000 cruzados em moedas para realizar negócios na Índia. Os navios enviados pela Companhia, em 1629, levavam 120.000 cruzados em média (SILVA, 1974, p. 181). Mas devemos ser cuidadosos com essas informaçôes. Afinal, esses valores foram calculados em moedas de conta, de modo que não sabemos ao certo que espécies eram efetivamente transportadas. Como se sabe, os navios portugueses carregavam normalmente moedas e barras de prata trazidas diretamente de Sevilha. Anthony Disney mostrou, em seu artigo, que no período do monopólio régio as remessas de moedas de ouro e prata foram maiores que durante a administração da Companhia. Nos anos entre 1611 e 1628, a média anual de espécies monetárias enviadas a Goa era de 96.250 cruzados. Entre 1628 e 1633, houve uma queda de quase $25 \%$ nestas remessas, ficando a média anual em 71.900 cruzados (DISNEY, 1977, p. 248).

A criação da Companhia, em agosto de 1628, deu-se em um contexto difícil para o Império Espanhol. Em setembro de 1628, o almirante Piet Heyn, da Companhia das Índias Ocidentais (West-Indische Compagnie - WIC), capturou a frota espanhola da prata na Baía de Matanzas que transportava uma carga avaliada em 11,5 milhóes de florins. Em moeda de conta portuguesa, podemos estimar em algo como 4,6 milhôes de cruzados. Segundo Charles Boxer, somente em prata, foram tomadas 177 mil libras (ou 354 mil marcos), valendo oito milhôes de florins. Além disso, havia 66 libras de ouro, e "muitas outras raridades": "cerca de 
ENTRADAS DE OURO E DE PRATA NA CASA DA MOEDA DE LISBOA (1604-1671) / em marcos

\begin{tabular}{|c|c|c|c|c|c|c|c|c|}
\hline & ouro & prata & & ouro & prata & & ouro & prata \\
\hline 1604 & 301 & 16.130 & 1627 & 752 & 130.350 & 1650 & 345 & 8.802 \\
\hline 1605 & & & 1628 & 1.745 & 98.090 & 1651 & 300 & 60.483 \\
\hline 1606 & 389 & 3.950 & 1629 & 144 & 20.920 & 1652 & 300 & 25.240 \\
\hline 1607 & 456 & 10.760 & 1630 & 255 & 41.910 & 1653 & 300 & 26.268 \\
\hline 1608 & 593 & 10.460 & 1631 & 217 & 16.770 & 1654 & 133 & 11.214 \\
\hline 1609 & 758 & 6.150 & 1632 & 43 & 22.490 & 1655 & 86 & 10.350 \\
\hline 1610 & 448 & 6.740 & 1633 & 153 & 3.760 & 1656 & 88 & 18.309 \\
\hline 1611 & 267 & 11.180 & 1634 & & & 1657 & 161 & 9.863 \\
\hline 1612 & 158 & 28.700 & 1635 & 356 & 270 & 1658 & & 6.715 \\
\hline 1613 & & & 1636 & 446 & 3.490 & 1659 & & 5.907 \\
\hline 1614 & 388 & 11.030 & 1637 & & & 1660 & & 5.883 \\
\hline 1615 & 859 & 13.400 & 1638 & 1.074 & 3.490 & 1661 & 339 & 2.713 \\
\hline 1616 & 226 & 26.690 & 1639 & 338 & 13.650 & 1662 & 3.319 & 1.524 \\
\hline 1617 & 84 & 34.160 & 1640 & 993 & 5.540 & 1663 & 8.501 & 213.337 \\
\hline 1618 & 283 & 14.520 & 1641 & 210 & 39.150 & 1664 & 914 & 65.059 \\
\hline 1619 & 176 & 8.490 & 1642 & 7.857 & 34.671 & 1665 & 169 & 27.405 \\
\hline 1620 & 108 & 13.080 & 1643 & 644 & 139.803 & 1666 & 1.666 & 29.007 \\
\hline 1621 & 44 & 5.090 & 1644 & 263 & 183.860 & 1667 & 1.667 & 34.667 \\
\hline 1622 & 100 & 2.780 & 1645 & 336 & 78.182 & 1668 & 14.112 & 34.667 \\
\hline 1623 & 399 & 19.800 & 1646 & 2.222 & 82.354 & 1669 & 3.821 & 5.641 \\
\hline 1624 & 595 & 36.973 & 1647 & 1.005 & 28.316 & 1670 & 1.938 & 207 \\
\hline 1625 & 392 & 55.900 & 1648 & 667 & 24.521 & 1671 & 1.074 & 228 \\
\hline 1626 & 462 & 30.150 & 1649 & 667 & 18.989 & & & \\
\hline
\end{tabular}

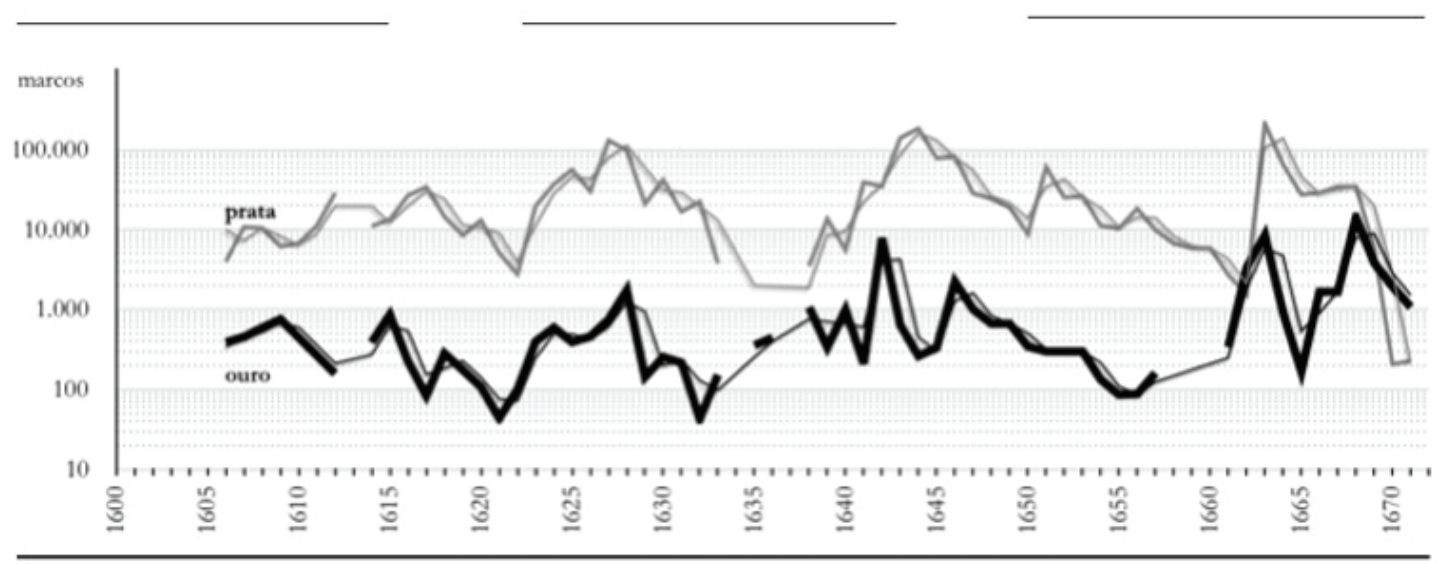

Fonte: Levantamento com base nos 109 volumes dos Registros das entradas de ouro e de prata do Arquivo Histórico da Casa da Moeda (Lisboa), feito por MAURO, 1989, v. 2, p. 182. Alguns números, segundo o historiador, são aproximaçóes. A escala do gráfico é logarítmica. Foram inseridas linhas de tendência. 
mil pérolas, quase dois milhôes de couros e grandes quantidades de seda, almíscar, âmbar e bezoar" (BOXER, 1961, p. 42). O butim encheu os cofres da WIC, permitiu um pagamento de 50\% de dividendos aos acionistas e ainda financiou uma nova expedição para conquistar o Brasil (HARING, 1918, p. 237-238). O revés levaria à suspensão de todos os pagamentos aos credores da monarquia e a uma dura crise financeira (VAN VEEN, 2000, p. 50-51). A partir de 1633, quando a Companhia de Comércio da Índia foi abolida, as entradas de prata na Casa da Moeda decrescem acentuadamente, dando a tônica para os anos seguintes que antecedem o golpe de dezembro de 1640. Com alguns anos sem registro e o ano de 1635 com apenas 270 marcos anotados, podemos estimar de forma generosa uma média anual de cerca de 5.300 marcos de prata. Nesses sete anos, se nos fiarmos nos dados levantados por Mauro, as oficinas em Lisboa náo poderiam cunhar mais que 148 mil cruzados.

A situação era reflexo, claramente, da crise mais geral das finanças da monarquia. Mesmo com a paz, iniciada com a Trégua dos Doze Anos (1609), os gastos militares permaneciam, e a fazenda de Espanha mantinha-se comprometida com despesas entre 8 e 9 milhóes de ducados por ano. Isto em um momento em que se notava a queda das remessas de prata da América. Como podemos ver na tabela acima, o último decênio do século XVI foi o auge dos envios do metal para Castela (2.707.627 quilos). Na primeira década dos Seiscentos, ainda que a produção tenha aumentado (segundo TePaske), os envios tiveram uma queda de cerca de $18 \%$ (2.213.631 quilos). Movimento que se manteve nos anos seguintes, acentuando-se na década de 1630 (1.396.760 quilos) e 1640 (1.056.431 quilos). Era já o prenúncio da crise. A pax hispanica, nos termos historiador Trevor-Roper, foi um momento de suspensão de todos os conflitos na Europa. O acordo entre os Habsburgos e as Províncias Unidas, em 1609, não apenas interrompia uma guerra de 80 anos, mas consolidava uma aparente vitória universal de Filipe III, apesar das derrotas contra a França, a Inglaterra e mesmo nos Países Baixos. Nas suas palavras, "era uma paz paradoxal, pois o vencedor universal era o poder que tinha sido derrotado universalmente". Em termos econômicos, a paz - que deve ser entendida como um "sistema social internacional" - era mais necessária para a Espanha, e, no entanto, "não poderia haver dúvida de que na década posterior a 1610, Filipe III parecia o monarca do mundo, mais poderoso através da paz do que seu pai havia sido pela guerra" (TREVOR-ROPER, 1970, p. 269-270) ${ }^{19}$. Mas, como lembrou Elliott, essa paz nunca se estendeu para o ultramar. Pelo contrário, os navios da República dos Países Baixos se aproveitaram para ganhar espaços e mercados, sobretudo do Império Português no Oriente, e se preparar para conquistar os territórios produtores de açúcar na América. Como disse, em 1616, Don Fernando de Carrillo, Presidente do

19 "This indeed was the essence of the Pax Hispanica, its strength and its weakness. It was not merely a set of political alliances: it was an international social system - static perhaps, parasitic perhaps, but deeply involved in social interests everywhere. Spain at war might be the enemy of the free states of Europe, but Spain at peace was the ally and example of a whole social class, and moreover of a possessing social class, within all those states". As traduçôes são minhas. 
Conselho da Fazenda, a paz "tem sido pior do que se a guerra continuasse" (ELLIOTT, 1963, p. 317) ${ }^{20}$.

\section{O fim da pax monetaria}

Quando olhamos para o sistema monetário português nessa terceira década do século XVII, a situação parecia agravar-se. No tempo de Filipe IV, o meio circulante em Portugal havia se enfraquecido com a saída do metal branco nos negócios com estrangeiros, sobretudo mercadores do Norte. Em troca de fazendas e trigo, a pouca prata que ainda circulava em Portugal ia sendo drenada para outros espaços econômicos. A situação do reino ainda piorou com a perda do Brasil para a WIC. Nesse contexto, em 26 de outubro de 1636, o comerciante cristão novo Simão de Souza ofereceu à monarquia emprestar 200 mil cruzados para o socorro do Brasil em troca do rendimento da Casa da Moeda, onde seria feita a refundição dos tostóes e meios-tostôes de prata. Sua proposta justifica o enfraquecimento das moedas como uma política necessária e útil para sustentar esse ganho fiscal e, como efeito secundário, manter a prata no reino. Ele, naturalmente, tinha grande expectativa de fazer um bom negócio, com ganhos elevados na troca das moedas fracas ou de Castela, por novas moedas nacionais, mas de menor peso (CÓPIA..., 26 out. 1636) ${ }^{21}$. Com efeito, já iam muitos anos que a Casa da Moeda estagnava, carente de metal para fundir, sem necessidade de interferir num meio circulante frágil e dominado por peças cunhadas em Espanha ou na América. No dia 30 de outubro, a governadora do reino, a Duquesa de Mântua, resolveu encaminhar uma consulta à mesa do Desembargo do Paço, para formar opinião sobre a proposta do comerciante. A posiçáo dos ministros foi exarada em um longo parecer, no qual se considerava os danos do alvitre de Simáo de Souza, nos termos de uma leitura contrária às práticas de mutação da moeda então muito forte no meio intelectual português. Para os conselheiros, era

[...] coisa certa que a substância da moeda consiste em sua forma, perfeita matéria e justo peso; e por consistir o valor intrínseco da moeda na dita perfeição da matéria e da justiça do peso, se lhe póem a forma que é o cunho em que se imprime ou a figura do príncipe ou suas armas e nome real, como fé autêntica e pública para segurar a todos que é composta a dita moeda de matéria perfeita e justo peso, e só com isso se despender e receber sem outra alguma experiência se havia de comerciar [...] de maneira que com isto ninguém o pode enjeitar ou revisar sob pena de grave castigo; e se debaixo da dita forma real e fé pública faltar o requisito intrínseco do

\footnotetext{
${ }^{20}$ Sobre isso, ver ainda PARKER, 1998 e ALLEN, 2000.

${ }^{21}$ Segundo James C. Boyajian, Simão de Souza estava envolvido no comércio de diamantes e pimenta nessas décadas iniciais do século XVII (BOYAJIAN, 1993, p. 217).
} 
peso justo se terá por vício contra a verdade, indigno de se aprovar, qualificar e autorizar com as armas, nome ou efígie real [...] (CONSULTA... [nov. ?], 1636).

Por outro lado, consideram que a moeda era a medida de todas as coisas, de modo que "também cresce ou diminuiu o preço das mesas coisas assim como se acrescenta ou diminui o dinheiro e sua estimaçáo". Dessa forma, o levantamento da moeda não surtiria o efeito desejado. Pior: essa alteração seria algo a agravar "a consciência dos príncipes", a menos que ela fosse feita "com o consentimento dos povos", que "se havia de haver por via de Cortes" (CONSULTA... [nov. ?], 1636).

A posição oresmiana, contrária à mutação da moeda pelo monarca e que reconhecia apenas nas cortes e nos povos o direito sobre a alteração dessa relação entre a moeda de conta e o valor do metal, parecia então muito difundida em Portugal ${ }^{22}$. Como sabemos, a mudança do valor das moedas, não obstante ser condenada por diversos estudiosos e homens práticos desde há muito tempo, era prática de que não se escusavam os monarcas e príncipes no medievo e na aurora da modernidade (DESMEDT e BLANC, 2010, p. 323-360). Entretanto, a decisão pela mudança no sistema monetário teria ainda de esperar a evolução da crise política que culminaria no golpe de $1^{\circ}$ de dezembro de 1640 . A intervenção no sistema monetário logo seria invocada por D. João IV e pelos seus homens no Conselho da Fazenda como uma solução rápida e eficiente para conseguir os recursos necessários para a guerra contra a Espanha ${ }^{23}$. A pax monetaria vivida desde as reformas de D. Sebastião em 1558-1560 e que perdurara por todo o período da União das Coroas, com a estabilidade da relação entre o valor intrínseco e o extrínseco das moedas metálicas, conheceria seu termo. Como a paz espanhola, essa "paz monetária" era um arranjo paradoxal. Como procuramos demonstrar, essa estabilidade do regime monetário português não significou uma consolidação do sistema monetário. Afinal, a presença elevada de peças cunhadas em Castela na massa monetária em Portugal, a dependência contínua do acesso à prata da América para garantir uma oferta de moedas - central para as atividades mercantis ultramarinas e, portanto, para a manutenção do próprio Império - tornavam esse equilíbrio um tanto fugaz. Paradoxalmente, se nas cor-

\footnotetext{
${ }^{22}$ Desde que, em meados do século XIV, o Bispo de Lisieux, Nicole Oresme, redigiu seu Tratado da Primeira Invenção das Moedas (Tractatus de origine, natura, jure et mutationibus monetarum), tem-se construído uma interpretação da impossibilidade moral da gestão do valor da moeda, porque ato contra a natureza e, portanto, contra Deus. Sua concepção era fundada em Aristóteles, que tinha a moeda como convenção: uma unidade de medida que serve como meio de troca, porque é estável. Nesse sentido, o dinheiro seria estéril para a produção de riqueza. A mutação da moeda, como forma de realizar um ganho, era comparada, entáo à usura. Além de se configurar, a alteração dos valores das moedas, uma ação contra os povos, os contratos e a propriedade privada. ORESME, 2004, p. 62). Sobre o assunto, veja o livro de BOYER, 2003, p. 4; GARCÍA GUERRA, 2000; e o estudo magistral de SPUFFORD, 1989. Veja também: BURNS, 1927, p. 468-471. Para uma leitura atenta da posição de Aristóteles, veja o artigo de ZELMANOVITZ, 2012, p. 61-83; a referência é uma passagem de Aristóteles na sua Ética a Nicômaco, 1979, p. 128.

${ }^{23}$ Sobre o assunto, veja meu artigo "A moeda na Restauração: da prática à política monetária em Portugal (1640-1642)", 2019, p. 34-57.
} 
tes em Tomar havia-se consagrado a autonomia do regime monetário português, a realidade das trocas mercantis e a conformação dos fluxos na economia-mundo, submetiam o sistema monetário português à hipertrofia da oferta castelhana. Com a Restauração, em 1640, foi justamente a consciência das distorçôes acumuladas no sistema monetário que daria oportunidade ao novo monarca de propor uma alteração no valor da moeda, de prata e de ouro, superando assim as resistências do pensamento monetário mais conservador. A Restauração irá aniquilar esta relativa pax monetaria e introduzir, de forma violenta e acelerada, uma política monetária mutacionista, preocupada inicialmente com a realização de ganhos fiscais para a manutençáo da guerra e do projeto de autonomia dos Braganças e, posteriormente, na consolidação de um sistema monetário efetivamente nacional.

\section{Fontes primárias}

ALVARÁ sobre a moeda cunhada por el-rei D. Antonio I. Reservados, MSS caixa 199, n. 86, (Biblioteca Nacional de Portugal), 4 fev. 1581.

ALVARÁ de 8 nov. 1612. Livro 1 de registo geral (1551-1687), fls. 138 e 138v (Arquivo Histórico da Casa da Moeda, Lisboa), 1612.

ALVARÁ de 13 set. 1606. Livro 1 de registo geral (1551-1687), fls. 123 e 123v (Arquivo Histórico da Casa da Moeda, Lisboa), 1606.

CONSULTA do Paço sobre a mudança da moeda que quis fazer Filipe III [IV]. Reservados, códice $11233^{32}$ (Biblioteca Nacional de Portugal), [novembro?] 1636.

CÓPIA do alvitre e papel que se fez sobre a moeda no tempo de Filipe IV e oferecimento de Simão de Souza sobre a moeda (emprestar 200 mil cruzados para o socorro do Brasil em troca do rendimento da Casa da Moeda, onde seria feita a refundição dos tostôes e meiostostôes de prata. Reservados, códice $11233^{32}$ (Biblioteca Nacional de Portugal), Madri, 26 out. 1636.

DESPACHO sugiriendo que se envie plata a Lisboa para acuñar moneda. Ms. 2657, fl. 74 (Biblioteca General Historica de la Universidad de Salamanca), 23 out. 1583.

LEI do ano de 1581 para que náo valha a moeda que se lavrou em nome de D. Antonio e que se corte e entregue a moeda. Elvas, 4 fev. 1581. In: SOUSA, Antonio Caetano de. História genealógica da Casa Real Portugueza, desde sua origem até o presente, com as familias ilustres, que precedem dos reis e dos serenissimos duques de Bragança. Lisboa: Officina de Joseph Antonio da Sylva, 1738, tomo IV, p. 336-338.

LEI do ano de 1584 sobre as moedas de ouro que se haviam de lavrar na casa da moeda desta cidade de Lisboa. Lisboa, 18 fev. 1584. In: SOUSA, Antonio Caetano. História genealógica da Casa Real Portugueza, desde sua origem até o presente, com as familias ilustres, que precedem 
dos reis e dos serenissimos duques de Bragança. Lisboa: Officina de Joseph Antonio da Sylva, 1738, tomo IV, p. 340-342.

LEI do ano de 1612 para que náo corram reales singelos sem serem examinados e cunhados de novo. Lisboa, 26 jan. 1612. In: SOUSA, Antonio Caetano. História genealógica da Casa Real Portugueza, desde sua origem até o presente, com as familias ilustres, que precedem dos reis e dos serenissimos duques de Bragança. Lisboa: Officina de Joseph Antonio da Sylva, 1738, tomo IV.

LEI de 1612 pela qual se ordena que dois reales singelos valha o marco 2.620 réis. Lisboa, 6 out. 1612. In: SOUSA, Antonio Caetano. História genealógica da Casa Real Portugueza, desde sua origem até o presente, com as familias ilustres, que precedem dos reis e dos serenissimos duques de Bragança. Lisboa: Officina de Joseph Antonio da Sylva, 1738, tomo IV.

\section{Referências}

ALLEN, Paul C. Philip III and the pax hispanica, 1598-1621: the failure of grand strategy. New Haven: Yale University Press, 2000.

AMARAL, Carlos Manuel Almeida de. Catálogo Descritivo das Moedas Portuguesas - Museu Numismático Português. Tomo 1. Lisboa: Imprensa Nacional - Casa da Moeda, 1977.

ARAGÃO, A. C. Teixeira de. Descrip̧̧ão geral e historica das moedas cunhadas em nome dos reis, regentes e governadores de Portugal. 3 v. Lisboa: Imprensa Nacional, 1875.

ARISTÓTELES. Ética a Nicômaco [século IV aC.]. Trad. Eudoro de Souza. São Paulo: Editora Abril, 1979.

BARRET, Ward. World billion flows, 1450-1800. In: TRACY, James D. (ed.). The rise of merchant empires. Cambridge, 1990. p. 224-254.

BOXER, Charles Ralph. Os holandeses no Brasil: 1624-1654. Rio de Janeiro: CEN, 1961.

BOYAJIAN, James C. Portuguese trade in Asia under the Habsburgs, 1580-1640. Balthmore: The Johns Hopkins University Press, 1993.

BOYER, Jerôme de. La pensée monétaire - histoire et analyse. Paris: Éditions Les Solos, 2003.

BRAUDEL, Fernand. Civilização material, economia e capitalismo. 3 v. São Paulo: Martins Fontes, 1996.

BURNS, A. R. Money and monetary policy in early times. Londres: Kegan Paul, Trench Tubner \& Co., 1927.

CARDIM, Pedro. Portugal unido y separado: Felipe II, la unión de territorios y el debate sobre la condición política del Reino de Portugal. Valladolid: Universidad de Valladolid, 2014. 
CHAILON, Renier Hubert Ghislain. D. Antonio, roi du Portugal, son histoire et ses monnaies. Bruxelas: Fr. Gobbaerts, 1868.

CIPOLLA, Carlo M. Conquistadores, piratas e mercadores: a saga da prata espanhola. Lisboa: Teorema, 1996.

COOPER, J. P. (ed.). The new Cambridge history. v. 4. Cambridge: Cambridge University Press, 1970.

CORDEIRO, P. Antonio. Historia insulana das ilhas a Portugal sugeytas no Oceano Occidental. Lisboa Occidental, na Officina de Antonio Pedrozo Galram, 1717.

COUVREUR, Raúl da Costa. Moeda portuguesa a espanhola. O marco na moeda de Castela e espanhola e na portuguesa. Revista Broteria. Lisboa, v. XXXVIII, p. 5-24, 1944.

COUVREUR, Raúl da Costa. Moeda espanhola e portuguesa: aditamento à nota sobre o marco na moeda de Castela e espanhola e na portuguesa. Revista Broteria, v. XL, p. 5-10, 1945.

DESMEDT, Ludovic; BLANC, Jérôme. Counteracting counterfeiting? Bodin, Mariana, and Locke on false money as a multidimensional issue. History of Political Economy, v. 42, n. 2, p. 323-360, 2010.

DISNEY, Anthony R. The first Portuguese India Company, 1628-33. Economic History Review, n. 30, p. 248, 1977.

DOMÍNGUEZ ORTIZ, Antonio. The golden age of Spain, 1516-1659. New York: Basic Books Inc., 1971.

ELLIOTT, John H. Imperial Spain 1469-1716. New York: The New American Library, 1963.

FLYNN, Dennis; GERALDEZ, Arturo. Cycles of silver: global economic unity through the Mid-Eighteenth Century. Journal of World History, n. 13, p. 391-427, 2002.

FRANCISCO OLMOS, José Maria de. Las armas de Portugal en las monedas de ma Monarquía Hispánica. Gaceta Numismatica, Barcelona, n. 172, p. 61-70, 2009.

FRANK, Andre Gunder. ReORIENT: global economy in the Asian Age. Berkeley: University of California Press, 1998.

GARCÍA GUERRA, Elena Maria. Las alteraciones monetarias en Europa durante la Edad Moderna. Madrid: Arco Libros, 2000.

GARNER, Richard L. Long-term silver mining trends in Spanish America: a comparative analysis of Peru and Mexico. The American Historical Review, n. 93, p. 898-935, 1988.

GODINHO, Vitorino Magalhães. Mito e mercadoria, utopia e prática de navegar - séculos XII-XVIII. Lisboa: Difel, 1990.

GODINHO, Vitorino Magalhães. Os descobrimentos e a economia mundial. 4 v. Lisboa: Presença, 1981. 
GODINHO, Vitorino Magalhães. Prix et monnaies au Portugal, 1750-1850. Paris: Éditions de l'EHESS, 1955.

HAMILTON, Earl J. The American treasure and the price revolution in Spain: 1501-1650. Cambridge: Harvard University Press, 1934.

HANKE, Lewis. The Imperial City of Potosi: an unwritten chapter in the history of Spanish America. Haia: Martinus Nijhoff, 1956.

HARING, Clarence Henry. Trade and navigation between Spain and the Indians in the time of Habsburgs. Cambridge: Cambridge University Press, 1918.

I BRU, Josep Pellicer. Iberian systems of weights in the Middle Ages: their hole in the monetary sphere. In: MARQUES, Mário Gomes (org.). Problems of medieval coinage in the Iberian area. Santarém, 1984. p. 105-119.

LANE, Kris. Potosi: the silver city that changed the world. Oakland: University of California Press, 2019.

MARICHAL, Carlos. La piastre ou le real de huit en Espagne et en Amérique: une monnaie universelle (XVIe-XVIIIe siècles). Revue Européenne des Sciences Sociales, n. 137, p. 107-121, 2007.

MARQUES, Mário Gomes (org.). Problems of Medieval Coinage in the Iberian Area. Santarém: Instituto Politécnico de Santarém, 1984.

MARSILIO, Claudio. Which way to turn?: the destinations of the Spanish silver (16211650): London, Lisbon, or Genoa?. Annales Mercaturae. Stuugart, Franz Steiner Verlag, n. 1; p. 9-35, 2015.

MAURO, Frédéric. Portugal, o Brasil e o Atlântico (1570-1670). 2 v. Lisboa: Editorial Estampa, 1989.

MENESES, D. Luís de (Conde de Ericeira). História de Portugal Restaurado. Lisboa, na officina de Domingos Rodrigues, 1751.

MOSQUERA DE FIGUEROA, Christoual. Comentario en breve compendio de disciplina militar, en que se escriue la jornada de las islas de los Açores. Madrid, por Luiz Sanchez, 1596. MUÑOZ SERRULLA, Maria Teresa. La moneda castellana en los reinos de indias durante la edad moderna. Madrid: Uned, 2015.

ORESME, Nicole. Pequeno tratado da primeira invenção das moedas (1355). Curitiba: Sagesta, 2004.

PARKER, Geoffrey. The grand strategy of Philip II. New Haven: Yale University Press, 1998. PUNTONI, Pedro. Da libra ao real: sobre a formaçấo do sistema monetário português (1185-1580). Revista de História, n. 178, p. 1-38, 2019.

PUNTONI, Pedro. A moeda na Restauração: da prática à política monetária em Portugal (1640-1642). Análise Social, n. 230, p. 34-57, 2019. 
REIS, Pedro Batalha. Numária d'el rei D. Antonio, décimo oitavo rei de Portugal o idolo do povo. Lisboa: Academia Portuguesa da História, 1946.

ROMANO, Ruggiero. Conjunctures Oposées, la "crise" de XVVe siècle en Europe et en Amérique Ibérique. Genebra: Droz, 1992.

SILVA, Chandra Richard da. The Portuguese East India Company 1628-1633. LusoBrazilian Review, n. 11, p. 181, 1974.

SOUSA, Antonio Caetano de. História genealógica da Casa Real Portugueza, desde sua origem até o presente, com as familias ilustres, que precedem dos reis e dos serenissimos duques de Bragança... Lisboa, na Officina de Joseph Antonio da Sylva, 1738, tomo IV.

SOUSA, Manuel de Faria e. Europa portuguesa. Lisboa, segunda edição, Antonio Craesbeeck, 1680.

SOUSA, Rita Martins de. Moeda e metais preciosos no Portugal setecentista (1688-1797). Lisboa: INCM, 2005.

SOUZA, José de Saldanha Oliveira e. Estatistica moedas de Ouro, Prata, Cobre e Bronze que se Cunharam na Casa da Moeda de Lisboa desde o $1^{\circ}$ de Janeiro de 1752 até 31 de Dezembro de 1871, segundo consta dos respectivos livros que existem na mesma repartição. Lisboa: Casa da Moeda, 1873.

SPUFFORD, Peter. Money and its use in Medieval Europe. Cambridge: Cambridge University Press, 1989.

STEIN, Stanley Jay; STEIN, Barbara H. Silver, trade and war: Spain and America in the making of Early Modern Europe. Baltimore: Johns Hopkins University Press, 2000.

TEPASKE, John J.; KLEIN, Herbert S. The royal treasures of Spanish Empire in América. 3 v. Durham: Duke University Press, 1982.

TEPASKE, John Jay. A new world of gold and silver. Leiden: Bril, 2010.

TRACY, James D. (ed.). The rise of merchant empires. Long-distance in the early modern world, 1350-1750. Cambridge: Cambridge University Press, 1990.

TREVOR-ROPER, H. R. Spain and Europe, 1598-1621. In: COOPER, J. P. (ed.). The new Cambridge history. V. 4. Cambridge, 1970.

VALLADARES, Rafael. A conquista de Lisboa: violência militar e comunidade política em Portugal, 1578-1583. Lisboa: Texto Editores, 2010.

VAN VEEN, Ernst. Defeat or decay? An inquiry into the Portuguese decline in Asia 15801645. Leiden: University of Leiden, 2000.

VISCONDE DE SANTARÉM. Memória para a história e theoria das cortes gerais. que em Portugal se celebraram pelos três Estados do Reino. Lisboa: Impressão Régia, 1828.

ZELMANOVITZ, Leonidas. Breve relato da história das ideias sobre moeda a partir de Aristóteles. Philiaß Filia, Porto Alegre, n. 2, p. 61-83, 2012. 